BMJ Open

Diabetes

Research

\& Care

\section{High probability of false-positive gestational diabetes mellitus diagnosis during early pregnancy}

To cite: Nakanishi S, Aoki S, Kasai J, et al. High probability of false-positive gestational diabetes mellitus diagnosis during early pregnancy. BMJ Open Diab Res Care 2020;8:e001234. doi:10.1136/ bmjdrc-2020-001234

- Additional material is published online only. To view please visit the journal online (http://dx.doi.org/10.1136/ bmjdrc-2020-001234).

Received 29 January 2020 Revised 12 June 2020 Accepted 16 June 2020

Check for updates

(c) Author(s) (or their employer(s)) 2020. Re-use permitted under CC BY-NC. No commercial re-use. See rights and permissions. Published by BMJ.

${ }^{1}$ Perinatal Center for Maternity and Neonate, Yokohama City University Medical Center, Yokohama, Kanagawa, Japan ${ }^{2}$ Department of Obstetrics and Gynecology, Yokohama Rosai Hospital, Yokohama, Kanagawa, Japan

${ }^{3}$ Department of Obstetrics and Gynecology, Saiseikai Yokohama-shi Nanbu Byoin, Yokohama, Kanagawa, Japan ${ }^{4}$ Department of Obstetrics and Gynecology, Fujisawa City Hospital, Fujisawa, Kanagawa, Japan

${ }^{5}$ Department of Obstetrics and Gynecology, Yokohama City University Hospital, Yokohama, Kanagawa, Japan

Correspondence to Dr Shigeru Aoki;

smyyaoki@yahoo.co.jp

\section{ABSTRACT}

Introduction This study aimed to assess the validity of applying the International Association of Diabetes and Pregnancy Study Group (IADPSG) criteria for the diagnosis of gestational diabetes mellitus (GDM) at any time during pregnancy.

Research design and methods This multicenter cohort study was conducted at five Japanese facilities from January 2018 to April 2019. The study cohort included women at a high risk of GDM who met one or more of the following IADPSG criteria during early pregnancy: fasting plasma glucose $(\mathrm{FPG}) \geq 92 \mathrm{mg} / \mathrm{dL}$ and $75 \mathrm{~g}$ oral glucose tolerance test (OGTT) value of $\geq 180 \mathrm{mg} / \mathrm{dL}$ at 1 hour, or $\geq 153 \mathrm{mg} / \mathrm{dL}$ at 2 hour (hereafter early-onset GDM). Women diagnosed with early-onset GDM were followed up without therapeutic intervention and underwent the $75 \mathrm{~g}$ 0GTT again during 24-28 weeks of gestation. Those exhibiting the GDM patterns on the second $75 \mathrm{~g}$ OGTT were diagnosed with true GDM and treated, whereas those exhibiting the normal patterns were diagnosed with false positive early GDM and received no therapeutic intervention.

Results Of the 146 women diagnosed with early-onset GDM, 69 (47\%) had normal $75 \mathrm{~g}$ 0GTT values at 24-28 weeks of gestation, indicating a false-positive result. FPG levels were significantly higher in the first $75 \mathrm{~g}$-0GTT test than in the second $75 \mathrm{~g}$-0GTT test $(93 \mathrm{mg} / \mathrm{dL}$ and $87.5 \mathrm{mg} / \mathrm{dL}$, respectively; $p<0.001)$. FPG levels were high in $86(59 \%)$ women with early-onset GDM during early pregnancy but in only $39(27 \%)$ women during mid-pregnancy. Compared with false positive early GDM, true GDM was more frequently associated with adverse pregnancy outcomes.

Conclusions Although women with early-onset GDM were followed up without treatment, the results of repeated $75 \mathrm{~g}$ OGTT during mid-pregnancy were normal in about $50 \%$. Our data did not support the adoption of IADPSG thresholds for the diagnosis of GDM prior to 20 weeks of gestation.

\section{INTRODUCTION}

Detection of gestational diabetes mellitus (GDM) is important for reducing the risks associated with maternal glucose intolerance. ${ }^{12}$ Although there is clear evidence that the diagnosis and treatment of GDM improve pregnancy outcomes, ${ }^{3}$ the efficacy of therapeutic interventions for GDM

\section{Significance of this study}

What is already known about this subject?

- The efficacy of therapeutic interventions for gestational diabetes mellitus (GDM) diagnosed during early pregnancy remains unclear. However, in 2013, the WHO recommended a diagnosis of GDM if the $75 \mathrm{~g}$ oral glucose tolerance test (OGTT) results at any time during pregnancy are equal to or exceed any of the following values (International Association of Diabetes and Pregnancy Study Group (IADPSG) criteria): fasting plasma glucose (FPG) level of $92 \mathrm{mg} /$ $\mathrm{dL}$, 1-hour value of $180 \mathrm{mg} / \mathrm{dL}$, and/or 2-hour value of $153 \mathrm{mg} / \mathrm{dL}$.

What are the new findings?

- About half of women who were diagnosed with GDM during early pregnancy according to IADPSG criteria had normal $75 \mathrm{~g}$ OGTT values at 24-28 weeks of gestation, without therapeutic intervention.

- In women with early-onset GDM, FPG levels significantly decreased from early pregnancy to $24-28$ weeks of gestation, whereas the 1-hour and 2-hour values remained virtually unchanged.

How might these results change the focus of research or clinical practice?

- IADPSG criteria for diagnosing GDM should not be adopted to the entire pregnancy period, including early pregnancy.

diagnosed during early pregnancy remains unclear.

In 2010, the International Association of Diabetes and Pregnancy Study Group (IADPSG) proposed the following criteria based on the Hyperglycemia and Adverse Pregnancy Outcome study: ${ }^{4}$ (a) GDM should be diagnosed if the results of the $75 \mathrm{~g}$ oral glucose tolerance test (OGTT) at 24-28 weeks of gestation are equal to or exceed any of the following values: fasting plasma glucose (FPG) level of $92 \mathrm{mg} / \mathrm{dL}$, 1-hour value of $180 \mathrm{mg} / \mathrm{dL}$, and/or 2-hour value of $153 \mathrm{mg} / \mathrm{dL}$ and (b) an FPG level of $92-125 \mathrm{mg} / \mathrm{dL}$ during early pregnancy 
should be classified as GDM. However, in response to reports from Italy ${ }^{5}$ and China, ${ }^{6}$ since 2016, the IADPSG does not recommend a diagnosis of GDM on the basis of an FPG level of $92-125 \mathrm{mg} / \mathrm{dL}$ during early pregnancy and issued a statement that the development of diagnostic criteria for abnormal glucose tolerance during early pregnancy is urgently needed. ${ }^{7}$

On the other hand, in 2013, the WHO recommended a diagnosis of GDM if the $75 \mathrm{~g}$ OGTT results are equal to or exceed any of the following values at any time during pregnancy: FPG level of 92-125 mg/dL, 1-hour value of $\geq 180 \mathrm{mg} / \mathrm{dL}$, and/or 2-hour value of $153-199 \mathrm{mg} / \mathrm{dL} .{ }^{3} \mathrm{In}$ Japan, the diagnostic criteria were changed in 2010 to those similar to the WHO criteria preceding the WHO's publication. Moreover, once GDM was diagnosed, therapeutic interventions were recommended, without the requirement of any further re-examinations. ${ }^{8}$ This change led to a dramatic increase in the number of women diagnosed with GDM, ${ }^{910}$ as well as the burden on such women and healthcare professionals in Japan. Nevertheless, the validity of diagnosing and treating GDM according to WHO 2013 criteria has not been evaluated.

Therefore, we are currently conducting a study to investigate the optimal Timing of Therapeutic Intervention for Gestational Diabetes Mellitus diagnosed in early pregnancy (TTIGDM study). In the present study, as a nested case-control study within the TTIGDM study, we examined the reproducibility of the OGTT results during early pregnancy and 24-28 weeks of gestation to evaluate the validity of the 2013 WHO criteria, which states that GDM should be diagnosed if the OGTT results are equal to or exceed any of the following values at any time during pregnancy: FPG level of $92 \mathrm{mg} / \mathrm{dL}$, 1-hour value of $180 \mathrm{mg} / \mathrm{dL}$, and/or 2-hour value of $153 \mathrm{mg} / \mathrm{dL}$.

\section{RESEARCH DESIGN AND METHODS}

The multicenter prospective cohort study was conducted at five secondary and tertiary medical facilities in Japan. As stated above, the TTIGDM study was initiated with the aim of determining the optimal timing of therapeutic intervention for gestational diabetes diagnosed in early pregnancy, and the present study is an interim report focusing on changes in blood glucose levels. The participating facilities and investigators are listed in the online supplementary appendix. We recruited 151 women with singleton pregnancies who were at a high risk of GDM between January 2018 and April 2019 at the participating facilities who underwent the $75 \mathrm{~g}$ OGTT before 20 weeks of gestation and exhibited signs of GDM patterns (meeting any of the following values: FPG level of $\geq 92 \mathrm{mg}$ / $\mathrm{dL}, 1$-hour value of $\geq 180 \mathrm{mg} / \mathrm{dL}$, and/or 2-hour value of $\geq 153 \mathrm{mg} / \mathrm{dL}$ ), which confirms the definitive diagnosis of early-onset GDM. Women with a random blood glucose level of $\geq 200 \mathrm{mg} / \mathrm{dL}$, FPG level of $\geq 126 \mathrm{mg} / \mathrm{L}$, or a hemoglobin A1c (HbAlc) level of $\geq 6.5 \% \quad(48 \mathrm{mmol} / \mathrm{mol}$ ) and those with a prior or current diagnosis of diabetes mellitus were excluded. The enrolled early-onset GDM women were followed up without therapeutic intervention, and they underwent the $75 \mathrm{~g}$ OGTT again (second $75 \mathrm{~g}$ OGTT) at 24-28 weeks of gestation (midpregnancy). All the study participants were fully informed about the possible disadvantages of not receiving any therapeutic intervention during the follow-up period, and they provided consent to participate in this study. Meanwhile, they received lifestyle instructions that are generally provided to pregnant women by maternity nurses and other healthcare professionals. Specifically, the study participants were instructed to follow a balanced diet. According to the guidelines issued by the Japanese Ministry of Health, Labour and Welfare, the following instructions on weight gain were provided: the optimal weight gain during pregnancy should be 9-12 kg for pregnant women with a prepregnancy body mass index (BMI) of $<18.5 \mathrm{~kg} / \mathrm{m}^{2}$ and $7-12 \mathrm{~kg}$ for those with prepregnancy BMIs of $\geq 18.5$ and $<25 \mathrm{~kg} / \mathrm{m}^{2}$. Those with a prepregnancy BMI of $\geq 25 \mathrm{~kg} / \mathrm{m}^{2}$ were instructed on a case-by-case basis, with an overall instruction to keep the weight gain around $5 \mathrm{~kg} .{ }^{11}$ Pregnant women exhibiting the GDM patterns on the second $75 \mathrm{~g}$ OGTT were diagnosed with true GDM and received nutrition therapy and insulin therapy, if needed. On the other hand, pregnant women not exhibiting the GDM patterns on the second $75 \mathrm{~g}$ OGTT were diagnosed with false GDM and received no therapeutic intervention.

In addition, during the follow-up observation before the second $75 \mathrm{~g}$ OGTT, all the study participants underwent clinical examinations and had HbAlc and a random blood glucose samples collected once per month. In case an HbAlc of $\geq 6.5 \%(48 \mathrm{mmol} / \mathrm{mol})$ or a random blood glucose level of $\geq 200 \mathrm{mg} / \mathrm{dL}$ was detected, they were excluded from the study and received treatment for GDM.

Pregnant women at a high risk of GDM were defined as those meeting any of the following conditions: random blood glucose level of $\geq 95 \mathrm{mg} / \mathrm{dL}$; prepregnancy body mass index (BMI) of $\geq 25 \mathrm{~kg} / \mathrm{m}^{2}$; positive urinary glucose; advanced maternal age at pregnancy ( $\geq 35$ years); family history of first or second-degree relatives with diabetes mellitus; previous history of large for gestational age (LGA) delivery, macrosomic delivery, or shoulder-dystocia delivery; previous history of perinatal loss or malformation of unknown causes; or previous history of GDM.

The maternal characteristics examined were maternal age, prepregnancy BMI, nulliparous rate $(\%)$, smoking during pregnancy, reasons for OGTT, and gestational age at the time of the $75 \mathrm{~g}$ OGTT during early and midpregnancy. The primary outcome was the reproducibility rate of the diagnosis of GDM by the second $75 \mathrm{~g}$ OGTT at mid-pregnancy. The secondary outcomes were changes in the results of the $75 \mathrm{~g}$ OGTT between early and midpregnancies. In addition, the maternal characteristics and pregnancy outcomes were compared between women who did not meet the diagnostic criteria for GDM based on the second $75 \mathrm{~g}$ OGTT results (ie, false GDM; early+/ late-) and women who met the diagnostic criteria for GDM (ie, true GDM; early+/late+). The comparison of 
the maternal characteristics included overall gestational weight gain, weight gain up to the second $75 \mathrm{~g}$ OGTT, fluctuations in HbAlc levels, and therapeutic strategies for GDM. The compared pregnancy outcomes included birth weight $(\mathrm{g})$; gestational age (weeks); and rates (\%) of cesarean delivery, emergency cesarean delivery, hypertensive disorders of pregnancy (HDP), preterm birth, macrosomia, shoulder dystocia, LGA, admission to the neonatal intensive care unit (NICU), neonatal hypoglycemia, hyperbilirubinemia, and respiratory distress syndrome (RDS). A diagnosis of HDP was established in pregnant women with a blood pressure of $\geq 140 / 90$ during pregnancy, according to the definition stipulated by the Japan Society for the Study of Hypertension in Pregnancy. ${ }^{12}$ Macrosomia was defined as birth weight $>4000 \mathrm{~g}$. LGA infants were defined as those with birth weight exceeding the 90th percentile based on the report from Neonate Committee of the Japan Pediatric Society. Neonatal hypoglycemia was defined as a blood glucose level of $<40 \mathrm{mg} / \mathrm{dL}$. Preterm birth was defined as birth before 37 weeks of gestation. Hyperbilirubinemia was defined as the requirement of phototherapy in an infant. Furthermore, RDS was defined as the presence of RDSspecific chest radiographic findings and requirement of oxygen administration within 24 hours of birth.

All data are presented as medians and were compared using the Wilcoxon signed-rank test, Mann-Whitney U test, and Fisher's exact test. A probability (p) value of $<0.05$ was considered statistically significant. Statistical analyses were performed using JMP Pro12 software (SAS Institute, Cary, North Carolina, USA).

\section{RESULTS}

In total, 151 women were enrolled in the study. Before the $75 \mathrm{~g}$ OGTT was repeated at 24-28 weeks of gestation, one woman experienced a miscarriage, two were transferred to another hospital, and two withdrew their consent. Thus, 146 women underwent a repeated $75 \mathrm{~g}$ OGTT. During the follow-up period, no woman exhibited poor glycemic control, as defined by a random blood glucose level of $\geq 200 \mathrm{mg} / \mathrm{dL}$ or HbAlc level of $\geq 6.5 \%$ (48 $\mathrm{mmol} / \mathrm{mol}$ ).

Table 1 lists the characteristics of the study participants during pregnancy. The median maternal age was 36 years, and the median prepregnancy BMI was $22.8 \mathrm{~kg} /$ $\mathrm{m}^{2}$. The most common risk factor for GDM as the reason for performing the $75 \mathrm{~g}$ OGTT in early pregnancy was older age ( $\geq 35$ years; $60.3 \%$ ), followed by high BMI $\left(\geq 25 \mathrm{~kg} / \mathrm{m}^{2} ; 34.9 \%\right)$ and a high random blood glucose level $(24 \%)$.

Of the 146 women diagnosed with GDM in early pregnancy (early-onset GDM), 69 (47.3\%) had normal results of the second $75 \mathrm{~g}$ OGTT performed at 24-28 weeks of gestation. In other words, the results of the second $75 \mathrm{~g}$ OGTT in about half of the women with early-onset GDM were false positive (ie, false positive early GDM).

Table 2 and figure 1 show changes in plasma glucose levels between the first and second $75 \mathrm{~g}$ OGTTs. In women with early-onset GDM, the median FPG level during the first $75 \mathrm{~g}$ OGTT was $93 \mathrm{mg} / \mathrm{dL}$, which was significantly higher than the median FPG level of $87.5 \mathrm{mg} / \mathrm{dL}$ of the second $75 \mathrm{~g}$ OGTT performed in mid-pregnancy $(\mathrm{p}<0.001)$. Compared with FPG levels in early pregnancy, that in mid-pregnancy decreased in 95/146 women $(65 \%)$. There was no significant difference in either the 1-hour or 2-hour values.

Table 3 shows the proportions of women with abnormal values of each $75 \mathrm{~g}$ OGTT parameter, namely, FPG, 1-hour value, and 2-hour value. In the first $75 \mathrm{~g}$ OGTT, 86/146 women $(59 \%)$ had an elevated FPG level, which was the most common reason for a diagnosis of GDM. In 51/146 women $(35 \%)$, GDM was diagnosed by an abnormally

\begin{tabular}{|c|c|c|}
\hline \multicolumn{2}{|c|}{ Median maternal age (years) (IQR) } & $36(33.8-39)$ \\
\hline \multicolumn{2}{|c|}{ Median prepregnancy BMI $\left(\mathrm{kg} / \mathrm{m}^{2}\right)(\mathrm{IQR})$} & $22.8(20.0-26.8)$ \\
\hline \multicolumn{2}{|c|}{ Gestational age at the time of the first $75 \mathrm{~g}$ OGTT before 20 weeks (weeks) (IQR) } & $14.7(13.9-17.1)$ \\
\hline \multicolumn{2}{|c|}{ Gestational age at the time of the second $75 \mathrm{~g}$ OGTT at $24-28$ weeks (weeks) (IQR) } & $26.1(25.3-27.1)$ \\
\hline \multicolumn{2}{|l|}{ Nullipara, $n(\%)$} & $62(43 \%)$ \\
\hline \multicolumn{2}{|c|}{ Smoking during pregnancy, $\mathrm{n}(\%)$} & $1(0.7 \%)$ \\
\hline Risk factors of GDM & Advanced maternal age & $94(60 \%)$ \\
\hline \multirow{6}{*}{ (Multiple responses included) } & $\mathrm{BMl}>25 \mathrm{~kg} / \mathrm{m}^{2}$ & $51(35 \%)$ \\
\hline & High value of random blood glucose & $35(24 \%)$ \\
\hline & Family history of type $2 \mathrm{DM}$ & $34(23 \%)$ \\
\hline & Previous history of GDM & $15(10 \%)$ \\
\hline & Positive urinary glucose & $5(3.4 \%)$ \\
\hline & $\begin{array}{l}\text { Previous history of macrosomic delivery, LGA delivery, } \\
\text { and shoulder-dystocia delivery }\end{array}$ & $3(2.1 \%)$ \\
\hline
\end{tabular}

BMI, body mass index; DM, diabetes mellitus; GDM, gestational diabetes mellitus; LGA, large for gestational age; OGTT, oral glucose tolerance test. 
Table 2 Comparison of median glucose levels $(\mathrm{mg} / \mathrm{dL}$ ) as determined with the $75 \mathrm{~g}$ OGTT (IQR) between before 20 weeks of gestation and 24-28 weeks of gestation

\begin{tabular}{lccc}
\hline & 75 $\mathbf{g}$ OGTT before 20 weeks & 75 g OGTT at 24-28 weeks & P value \\
\hline FPG & $93(88-95)$ & $87.5(82-92)$ & $<0.001$ \\
1-hour value & $162(129-185)$ & $159(131-180)$ & 0.98 \\
2-hour value & $149(116-167)$ & $136.5(113-157)$ & 0.21 \\
\hline
\end{tabular}

The study participants were instructed to fast for 10 hours before the $75 \mathrm{~g}$ OGTT.

FPG, fasting plasma glucose; OGTT, oral glucose tolerance test.

high FPG level alone. On the other hand, 37/146 women (27\%) had an abnormally high FPG levels on the second $75 \mathrm{~g}$ OGTT.

Table 4 shows the pregnancy outcomes of the women with false positive early GDM and true GDM. Compared with the women false positive early GDM, those with true GDM had significantly higher prepregnancy BMIs and higher HbAlc levels at all time points including baseline, second OGTT, and delivery. In particular, there were significantly more women with true GDM among those with a prepregnancy BMI of $\geq 25 \mathrm{~kg} / \mathrm{m}^{2}(\mathrm{p}=0.016)$. The degree of weight gain up to the second OGTT was equivalent between the women with false positive early GDM and true GDM (4 kg vs $4.5 \mathrm{~kg}$ ); furthermore, the degree of weight gain up to delivery was non-significantly larger in the women with false positive early GDM $(8.9 \mathrm{~kg}$ vs $7.7 \mathrm{~kg}$ ). Regarding the pregnancy outcomes, the rates of preterm birth and NICU admission were significantly higher in the women with true GDM. Although not significantly different, the rate of LGA infants was higher in the women with true GDM. Overall, the pregnancy outcomes were poor in the women with true GDM.

\section{DISCUSSION}

When standard IADPSG thresholds are applied to the $75 \mathrm{~g}$ OGTT performed at $<20$ weeks of gestation in women at risk of developing GDM, nearly half of those with at least one abnormal value in early pregnancy, will have normal test results when repeated at 24-28 weeks of gestation.

In 2010, IADPSG stated that during early pregnancy, GDM is diagnosed if FPG is $92-125 \mathrm{mg} / \mathrm{dL}$. However, in previous reports, $60 \%$ of pregnant women with an FPG level of $\geq 92 \mathrm{mg} / \mathrm{dL}$ during early pregnancy did not have high FPG levels, as determined with the $75 \mathrm{~g}$ OGTT, at 24-28 weeks of gestation, ${ }^{6}$ and $55 \%$ of those with high FPG levels during early pregnancy were not diagnosed as having GDM at 24-28 weeks of gestation. ${ }^{5}$ In response to
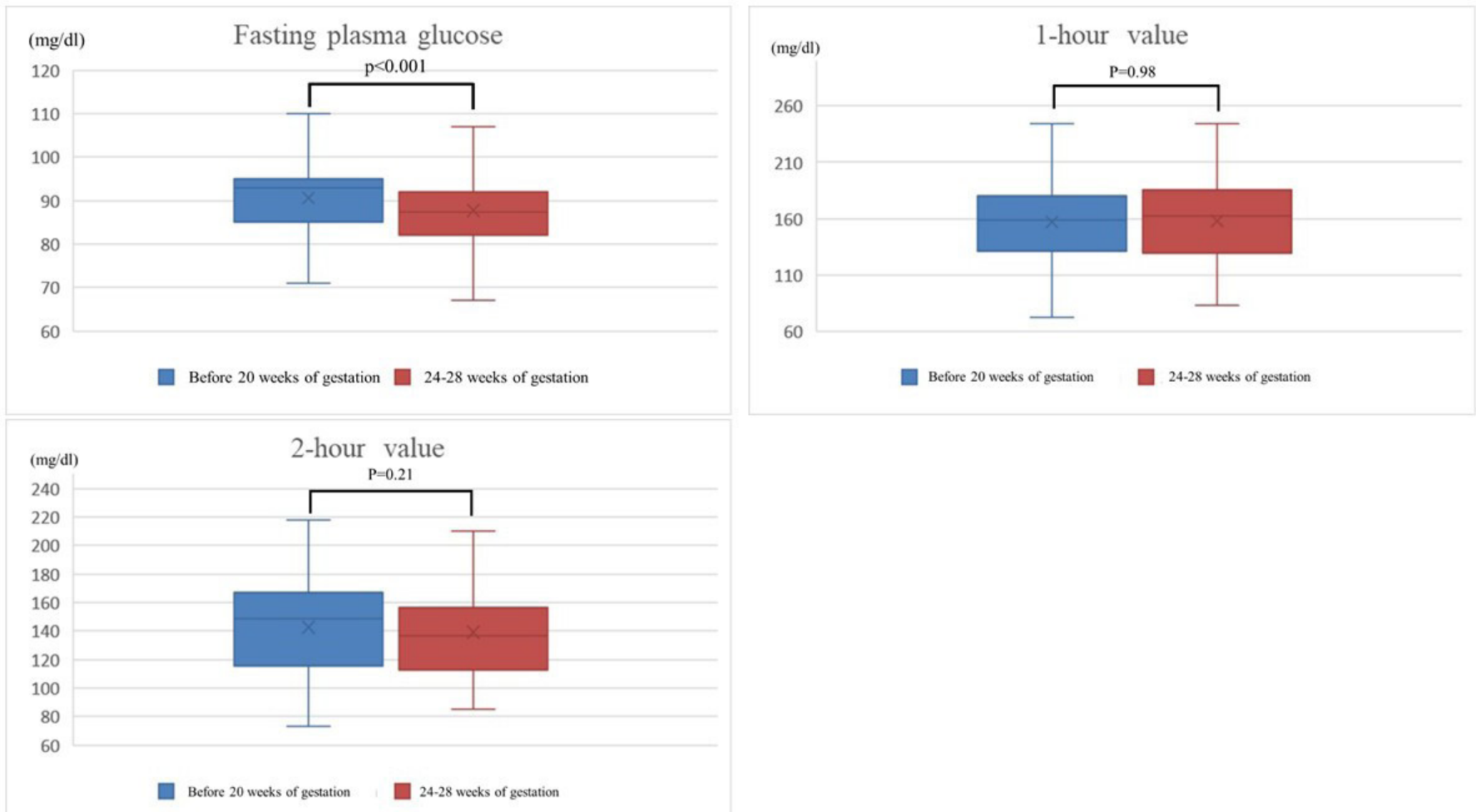

Figure 1 Comparison of glucose levels $(\mathrm{mg} / \mathrm{dL})$ as determined with the $75 \mathrm{~g}$ OGTT between before 20 weeks of gestation and 24-28 weeks of gestation. OGTT, oral glucose tolerance test. 
Table 3 The number of subjects with individual glucose measures $\geq$ threshold

\begin{tabular}{lll}
\hline & $\begin{array}{l}\text { 75 g OGTT before 20 } \\
\text { weeks of gestation }\end{array}$ & $\begin{array}{l}\text { 75 g OGTT at 24-28 } \\
\text { weeks of gestation }\end{array}$ \\
\hline FPG & $86(59 \%)$ & $39(27 \%)$ \\
1-hour value & $47(32 \%)$ & $38(26 \%)$ \\
2-hour value & $67(46 \%)$ & $42(29 \%)$ \\
\hline
\end{tabular}

FPG, fasting plasma glucose; OGTT, oral glucose tolerance test.

these reports, the IADPSG withdrew the criteria for FPG levels in respect to early-onset GDM in 2016. Mills et $\mathrm{l}^{13}$ reported that FPG levels decrease physiologically as pregnancy progresses. The results of the present study, which was limited to Japanese pregnant women, were consistent with these results. In Japan, the same criteria as the WHO criteria are adopted. However, given that about half of women with early-onset GDM have false positive early GDM, which is diagnosed based on normal blood glucose patterns during re-examination at 24-28 weeks of gestation, the WHO diagnostic criteria should be reviewed.

The clinical significance of early-onset GDM still remains unknown. Sweeting $e a^{14}$ reported that in women at a high risk of GDM, early-onset GDM was associated with poor pregnancy outcomes that were more comparable with those of women with type 2 diabetes mellitus rather than those with late-onset GDM diagnosed at or after 24-28 weeks of gestation. On the other hand, Hong et $a l^{15}$ found no benefit of a diagnosis of early-onset GDM in pregnant women at a high risk of GDM. In Japan, Hagiwara $e t a l^{16}$ reported no differences in the pregnancy outcomes between women with early-onset GDM treated from early pregnancy and those with late-onset GDM diagnosed and treated during or after 24-28 weeks

Table 4 Maternal characteristics and pregnancy outcomes of women with false positive early GDM (early+/late-) and true GDM (early+/late+)

\begin{tabular}{|c|c|c|c|c|}
\hline & $\begin{array}{l}\text { False positive early GDM } \\
\text { (early+/late-) } n=69\end{array}$ & $\begin{array}{l}\text { True GDM } \\
\text { (early+/late+) n=77 }\end{array}$ & $P$ value & OR $(95 \% \mathrm{Cl})$ \\
\hline Maternal age (years) & $37(19-47)$ & $36(23-45)$ & 0.62 & \\
\hline Prepregnancy BMl: $<18.5 \mathrm{~kg} / \mathrm{m}^{2}$ & $8(11.6 \%)$ & $5(6.5 \%)$ & 0.39 & \\
\hline Prepregnancy BMI: $18.5-25 \mathrm{~kg} / \mathrm{m}^{2}$ & $44(63.8 \%)$ & $38(49.4 \%)$ & 0.096 & \\
\hline Smoking during pregnancy & $1(1.4 \%)$ & $0(0 \%)$ & & \\
\hline Weight gain until second OGTT (kg) & $4(-9.3-15)$ & $4.5(-4.8-15.8)$ & 0.75 & \\
\hline Weight gain until delivery (kg) & $8.9(-11-19.2)$ & $7.7(-5.0-18.0)$ & 0.25 & \\
\hline HbA1c on baseline (\%) & $5.2(4.6-5.9)$ & $5.4(4.6-6.3)$ & $<0.001$ & \\
\hline Insulin therapy (\%) & Not applicable & $21(27 \%)$ & & \\
\hline Hypertensive disorders of pregnancy (\%) & $12(17 \%)$ & $13(17 \%)$ & 1.00 & \\
\hline Birth weight (g) & $3002(1896-3786)$ & $2976(1552-4058)$ & 0.66 & \\
\hline Gestational age (weeks) & $39.3(34.0-42.1)$ & $38.7(33.8-41.7)$ & 0.009 & \\
\hline Preterm birth & $1(1.4 \%)$ & $10(12 \%)$ & 0.010 & 0.0985 (0.0122 to 0.791$)$ \\
\hline Macrosomia & $0(0 \%)$ & $1(1.3 \%)$ & & \\
\hline Shoulder dystocia & $0(0 \%)$ & $1(1.3 \%)$ & & \\
\hline Large for gestational age & $6(8.7 \%)$ & $15(20 \%)$ & 0.10 & 0.394 (0.143 to 1.080$)$ \\
\hline Cesarean delivery & $29(42 \%)$ & $25(32 \%)$ & 0.30 & 1.508 (0.767 to 2.963$)$ \\
\hline
\end{tabular}

The values are expressed as mean (range) or number (\%).

BMI, body mass index; GDM, gestational diabetes mellitus; HbA1c, glycated hemoglobin; NICU, neonatal intensive care unit; OGTT, oral glucose tolerance test. 
of gestation and concluded that the diagnostic criteria for GDM should probably be applied only at 24-28 weeks of gestation, rather than throughout pregnancy. A systematic review and meta-analysis of the screening and treatment for early-onset $\mathrm{GDM}^{17}$ also concluded that the therapeutic effects on early-onset GDM are dubious and that randomized controlled trials investigating the therapeutic effects on early-onset GDM are urgently required.

In response to the findings of a large-scale cohort study conducted on the association between HbAlc levels during early pregnancy and pregnancy outcomes in New Zealand, ${ }^{18}$ the IADPSG stated that early-onset GDM may be defined as a $\mathrm{HbAlc}$ level of $\geq 5.9 \%(41 \mathrm{mmol} / \mathrm{mol})$ in early pregnancy instead of an FPG level of $92-125 \mathrm{mg}$ / $\mathrm{dL} .{ }^{7}$ In the present study, HbAlc levels had been significantly higher since the baseline in the women with true GDM than in those with false positive early GDM. This may support the validity of the new IADPSG proposal. Given the finding of this study that the 1-hour and 2-hour values of the $75 \mathrm{~g}$ OGTT were almost comparable between early pregnancy and 24-28 weeks of gestation, it seems that a 1 -hour value of $\geq 180 \mathrm{mg} / \mathrm{dL}$ or 2 -hour value of $\geq 153 \mathrm{mg} / \mathrm{dL}$ should be regarded as a high risk of a diagnosis of GDM at 24-28 weeks of gestation, or in other words, booking GDM. Because there were significantly more women with true GDM among those with a prepregnancy BMI of $\geq 25 \mathrm{~kg} / \mathrm{m}^{2}$, the presence of obesity in combination with the above conditions should be regarded as being linked to a higher risk of diagnosis of GDM during 24-28 weeks of gestation.

The pregnancy outcomes were overall poorer in the women with true GDM who exhibited the GDM patterns during early pregnancy and during 24-28 weeks of gestation than in those with false positive early GDM who exhibited the GDM patterns only during early pregnancy. Because false positive early GDM was not regarded as GDM during pregnancy, the women with false positive early GDM did not receive any therapeutic intervention. On the other hand, true GDM had been treated as GDM since mid-pregnancy, and the women with true GDM received therapeutic interventions including nutrition therapy and insulin therapy. Nevertheless, the rate of LGA infants was higher $(20 \%)$ in the women with true GDM, although the difference was not significant. Conversely, the delivery rate of LGA infants in the women with false positive early GDM was $8.7 \%$, which is comparable with the rate expected in the general population. These results suggest that no therapeutic interventions are necessary for women with false positive early GDM who exhibit GDM patterns only during early pregnancy.

There were some limitations to this study that should be addressed. First, all of the study participants were Japanese. Because GDM prevalence and glucose tolerance vary among different populations, ${ }^{19}$ the results of the present study will not necessarily be applicable to other populations. Second, certain selection bias was noted in this study. This study included pregnant women at a high risk of GDM who were diagnosed with GDM based on
75 g OGTT during early pregnancy; therefore, the study participants were not selected via universal screening. Because there are pregnant women without any risk factors who are diagnosed with GDM, ${ }^{20}{ }^{21}$ the present study results may not be applicable to all pregnant women with GDM. Third, because this was a prospective study, the participating women themselves were aware that they would be diagnosed as having GDM under usual circumstances in Japan. Hence, it is possible that the women unconsciously improved some lifestyle factors. However, because the degree of weight gain during follow-up without treatment up to 24-28 weeks of gestation was almost similar between the women with true and false positive early GDM, it can be assumed that there was almost no impact on weight gain; this could imply that both groups implemented similar lifestyle. Finally, the results of the glucose tolerance test are known to be imprecise because of poor reproducibility in itself. ${ }^{22}$ However, to the best of our knowledge, this is the first prospective study in pregnant women with early-onset GDM to investigate whether the results of the $75 \mathrm{~g}$ OGTT in early pregnancy were reproducible at 24-28 weeks of gestation, when GDM should be diagnosed according to the recommendation of the IADPSG.

In conclusion, although women with early-onset GDM were followed up without treatment, the results of repeated $75 \mathrm{~g}$ OGTT during mid-pregnancy were normal in about $50 \%$. Our data did not support the adoption of IADPSG thresholds for the diagnosis of GDM prior to 20 weeks of gestation.

Acknowledgements The authors thank Dr Mitsuyoshi Ota from the Y-NEXT (YCU Center for Novel and Exploratory Clinical Trials) for his valuable comments.

Contributors SN researched data and wrote the manuscript. SA contributed to study design and wrote the manuscript. JK contributed to study design and researched data. $\mathrm{RS}$ and $\mathrm{SO}$ researched data. $\mathrm{YH}$ and $\mathrm{AM}$ researched data and recruited the subjects. EM finalized the manuscript.

Funding The research was partially supported by JSPS KAKENHI (grant number JP1919K18675).

Competing interests The facilities (participating investigators) that participated in this study included the Yokohama City Medical Center (SN, SA, RS, and S0), Yokohama City University Hospital (EM), Yokohama Rosai hospital (JK), Fujisawa City Hospital (AM and Haruya Saji), and Saiseikai Yokohama Nanbu Hospital (YH and Masaya Endo).

Patient consent for publication Not required.

Ethics approval The study protocol was approved by the Ethics Committee of the Yokohama City University Medical Center (approval no. B171102004).

Provenance and peer review Not commissioned; externally peer reviewed.

Data availability statement No data are available.

Open access This is an open access article distributed in accordance with the Creative Commons Attribution Non Commercial (CC BY-NC 4.0) license, which permits others to distribute, remix, adapt, build upon this work noncommercially, and license their derivative works on different terms, provided the original work is properly cited, appropriate credit is given, any changes made indicated, and the use is non-commercial. See: http://creativecommons.org/ licenses/by-nc/4.0/.

ORCID iD

Sayuri Nakanishi http://orcid.org/0000-0002-3694-4340 


\section{REFERENCES}

1 Crowther CA, Hiller JE, Moss JR, et al. Effect of treatment of gestational diabetes mellitus on pregnancy outcomes. N Engl J Med 2005;352:2477-86.

2 Landon MB, Spong CY, Thom E, et al. A multicenter, randomized trial of treatment for mild gestational diabetes. $N$ Engl J Med 2009;361:1339-48.

3 Diagnostic criteria and classification of hyperglycaemia first detected in pregnancy: a world Health organization guideline. Diabetes Res Clin Pract 2014;103:341-63.

4 HAPO Study Cooperative Research Group, Metzger BE, Lowe LP, et al. Hyperglycemia and adverse pregnancy outcomes. N Engl J Med 2008;358:1991-2002.

5 Corrado F, D'Anna R, Cannata ML, et al. Correspondence between first-trimester fasting glycaemia, and oral glucose tolerance test in gestational diabetes diagnosis. Diabetes Metab 2012;38:458-61.

6 Zhu W-W, Yang H-X, Wei Y-M, et al. Evaluation of the value of fasting plasma glucose in the first prenatal visit to diagnose gestational diabetes mellitus in China. Diabetes Care 2013;36:586-90.

7 Mclntyre HD, Sacks DA, Barbour LA, et al. Issues with the diagnosis and classification of hyperglycemia in early pregnancy. Diabetes Care 2016;39:53-4.

8 Committee of the Japan Diabetes Society on the Diagnostic Criteria of Diabetes Mellitus, Seino Y, Nanjo K, et al. Report of the Committee on the classification and diagnostic criteria of diabetes mellitus. J Diabetes Investig 2010;1:212-28.

9 Morikawa M, Yamada T, Yamada T, et al. Change in the number of patients after the adoption of IADPSG criteria for hyperglycemia during pregnancy in Japanese women. Diabetes Res Clin Pract 2010;90:339-42.

10 Ikenoue S, Miyakoshi K, Saisho Y, et al. Clinical impact of women with gestational diabetes mellitus by the new consensus criteria: two year experience in a single institution in Japan. Endocr $J$ 2014;61:353-8.

11 Press release from The Ministry of Labour, Health and Welfare. Optimal weight gain during pregnancy [translated from Japanese], 2006. Available: https://www.mhlw.go.jp/houdou/2006/02/dl/h02013a4.pdf
12 Watanabe K, Matsubara K, Nakamoto O, et al. Outline of the new definition and classification of "Hypertensive Disorders of Pregnancy (HDP)"; a revised JSSHP statement of 2005. Hypertens Res Pregnancy 2018;6:33-7.

13 Mills JL, Jovanovic L, Knopp R, et al. Physiological reduction in fasting plasma glucose concentration in the first trimester of normal pregnancy: the diabetes in early pregnancy study. Metabolism 1998;47:1140-4.

14 Sweeting AN, Ross GP, Hyett J, et al. Gestational diabetes mellitus in early pregnancy: evidence for poor pregnancy outcomes despite treatment. Diabetes Care 2016;39:75-81.

15 Hong WY, Biggio JR, Tita A, et al. Impact of early screening for gestational diabetes on perinatal outcomes in high-risk women. Am J Perinatol 2016;33:758-64.

16 Hagiwara Y, Kasai J, Nakanishi S, et al. Should the IADPSG criteria be applied when diagnosing early-onset gestational diabetes? Diabetes Res Clin Pract 2018;140:154-61.

17 Immanuel J, Simmons D. Screening and treatment for early-onset gestational diabetes mellitus: a systematic review and meta-analysis. Curr Diab Rep 2017;17:115.

18 Hughes RCE, Moore MP, Gullam JE, et al. An early pregnancy $\mathrm{HbA} 1 \mathrm{c} \geq 5.9 \%$ (41 $\mathrm{mmol} / \mathrm{mol}$ ) is optimal for detecting diabetes and identifies women at increased risk of adverse pregnancy outcomes. Diabetes Care 2014;37:2953-9.

19 Sacks DA, Hadden DR, Maresh M, et al. Frequency of gestational diabetes mellitus at collaborating centers based on IADPSG consensus panel-recommended criteria: the hyperglycemia and adverse pregnancy outcome (HAPO) study. Diabetes Care 2012;35:526-8.

20 Avalos GE, Owens LA, Dunne F, et al. Applying current screening tools for gestational diabetes mellitus to a European population: is it time for change? Diabetes Care 2013;36:3040-4.

21 Chevalier N, Fénichel P, Giaume V, et al. Universal two-step screening strategy for gestational diabetes has weak relevance in French Mediterranean women: should we simplify the screening strategy for gestational diabetes in France? Diabetes Metab 2011;37:419-25

22 Riccardi G, Vaccaro O, Rivellese A, et al. Reproducibility of the new diagnostic criteria for impaired glucose tolerance. Am J Epidemiol 1985;121:422-9. 